\title{
Spontaneous resolution of avascular necrosis of femoral heads following cure of Cushing's syndrome
}

\author{
A Pazderska1, S Crowther ${ }^{2}$, P Govender 3 , K C Conlon ${ }^{4,6}$, M Sherlock ${ }^{1,5}$ and J Gibney ${ }^{1,5}$ \\ Departments of ${ }^{1}$ Endocrinology, ${ }^{2}$ Cellular Pathology, ${ }^{3}$ Radiology, ${ }^{4}$ Professional Surgical Unit, Adelaide \\ and Meath Hospitals, incorporating the National Children's Hospital, Tallaght, Dublin 24, Ireland, \\ Departments of ${ }^{5}$ Endocrinology and ${ }^{6}$ Surgery, Trinity College, Dublin, Ireland
}

\author{
Correspondence \\ should be addressed \\ to A Pazderska \\ Email \\ agnieszkapazderska@ \\ gmail.com
}

\section{Summary}

Avascular necrosis (AVN) is a rare presenting feature of endogenous hypercortisolism. If left untreated, complete collapse of the femoral head may ensue, necessitating hip replacement in up to $70 \%$ of patients. The majority of the described patients with AVN due to endogenous hypercortisolaemia required surgical intervention. A 36-year-old female, investigated for right leg pain, reported rapid weight gain, bruising and secondary amenorrhoea. She had abdominal adiposity with violaceous striae, facial plethora and hirsutism, atrophic skin, ecchymosis and proximal myopathy. Investigations confirmed cortisol excess (cortisol following low-dose $48 \mathrm{~h}$ dexamethasone suppression test $807 \mathrm{nmol} / \mathrm{L} ; 24 \mathrm{~h}$ urinary free cortisol $1443 \mathrm{nmol}$ (normal $<290 \mathrm{nmol}$ )). Adrenocorticotrophic hormone (ACTH) was $<5.0 \mathrm{pg} / \mathrm{mL}$. CT demonstrated subtle left adrenal gland hypertrophy. Hypercortisolaemia persisted after left adrenalectomy. Histology revealed primary pigmented micronodular adrenal disease. Post-operatively, right leg pain worsened and left leg pain developed, affecting mobility. MRI showed bilateral femoral head AVN. She underwent right adrenalectomy and steroid replacement was commenced. Four months after surgery, leg pain had resolved and mobility was normal. Repeat MRI showed marked improvement of radiological abnormalities in both femoral heads, consistent with spontaneous healing of AVN. We report a case of Cushing's syndrome due to primary pigmented nodular adrenocortical disease, presenting with symptomatic AVN of both hips. This was managed conservatively from an orthopaedic perspective. Following cure of hypercortisolaemia, the patient experienced excellent recovery and remains symptom free 4 years after adrenalectomy. This is the first report of a favourable outcome over long-term follow-up of a patient with bilateral AVN of the hip, which reversed with treatment of endogenous hypercortisolaemia.

\section{Learning points:}

- AVN of femoral head can be a presenting feature of hypercortisolism, both endogenous and exogenous.

- Rarely, treatment of hypercortisolaemia can reverse AVN without the need for orthopaedic intervention.

- Primary pigmented nodular adrenal disease is a rare cause of ACTH-independent Cushing's syndrome.

\section{Background}

Our case will be of interest to other clinicians in the field as it has a number of unique elements. Avascular necrosis (AVN) is a very rare presenting feature of endogenous hypercortisolaemia. Previously published cases almost exclusively reported outcomes requiring orthopaedic intervention; in our case, AVN resolved with treatment of the underlying pathology causing cortisol excess. Furthermore, to our knowledge, this is the first case to report long-term follow-up of non-surgical management of AVN of the hip due to endogenous hypercortisolaemia. 


\section{Case presentation}

A 36-year-old female was admitted under orthopaedic surgery to investigate right leg pain. Lumbar spine MRI showed a left paracentral disc herniation at L4/L5 level. She underwent L4/L5 discectomy with modest symptomatic improvement. Incidental findings of an early L1 compression fracture and multiple rib fractures were made; there was no history of trauma.

Given her premature osteoporosis, an endocrinology opinion was sought. The patient reported weight gain, secondary amenorrhoea of 2 year duration and a recent onset of facial hirsutism. On examination, she had abdominal adiposity with violaceous striae, facial plethora and hirsutism, atrophic skin, multiple ecchymoses and proximal muscle weakness consistent with Cushing's syndrome. She had never used exogenous steroids.

\section{Investigation}

Biochemical investigations confirmed cortisol excess with 09:00 h cortisol following a $1 \mathrm{mg}$ overnight dexamethasone suppression test of $747 \mathrm{nmol} / \mathrm{L}$ and cortisol following lowdose $48 \mathrm{~h}$ dexamethasone suppression test of $807 \mathrm{nmol} / \mathrm{L}$. Two $24 \mathrm{~h}$ urinary collections showed free cortisol of 1263 and $1443 \mathrm{nmol}$ (reference $\leq 290 \mathrm{nmol} / 24 \mathrm{~h}$ ). Adrenocorticotrophic hormone (ACTH) was supressed at $<5.0 \mathrm{pg} / \mathrm{mL}$ consistent with an ACTH-independent source of Cushing's syndrome. Non-contrast dedicated CT adrenal glands showed possible subtle hypertrophy of the left adrenal gland and a radiologically normal right adrenal gland.

The diagnosis of micronodular adrenal hyperplasia was considered, and the patient underwent sequential lowdose, high-dose dexamethasone suppression test with $24 \mathrm{~h}$ urine collection for measurements of free cortisol (Liddle's test: collection on day 1-2 for baseline measurement, day 3-4 during low-dose dexamethasone suppression test and day 5-6 during high-dose dexamethasone suppression test). In $69-75 \%$ of patients with cortisol excess due to primary pigmented nodular adrenocortical disease, there is a paradoxical $50 \%$ rise in $24 \mathrm{~h}$ urinary cortisol excretion on day 6 of the test (1). However, in our patient, Liddle's test failed to show a rise in cortisol excretion (day $1-1443 \mathrm{nmol}$, day $2-1700 \mathrm{nmol}$, day $3-1526 \mathrm{nmol}$, day $4-1071 \mathrm{nmol}$, day $5-945 \mathrm{nmol}$ and day $6-877 \mathrm{nmol}$ ).

\section{Treatment}

She underwent laparoscopic left adrenalectomy but remained hypercortisolaemic after surgery: morning cortisol on day 4 post surgery was $293 \mathrm{nmol} / \mathrm{L}$; cortisol post $1 \mathrm{mg}$ dexamethasone suppression test was $306 \mathrm{nmol} / \mathrm{L}$. Post-operatively, her right leg pain worsened and left leg pain developed, affecting ambulation. MRI of hips showed bilateral AVN of the femoral heads with early bone fragmentation on the left (Fig. 1A and B). Surgical core decompression of the left femoral head was deferred, in favour of a right-sided adrenalectomy. Histology of both adrenal glands showed multifocal nodular hyperplasia and brown pigment consistent with a diagnosis of primary pigmented micronodular adrenal disease, which is a rare cause of ACTH-independent Cushing's syndrome causing bilateral adrenal pathology. Long-term steroid replacement with $15 \mathrm{mg}$ hydrocortisone was commenced.

\section{Outcome and follow-up}

Following adrenalectomy, the patient was under regular orthopaedic follow-up, and as symptoms of bilateral leg pain continued to improve, orthopaedic intervention was withheld in keeping with the patient's preference. This approach seems to be justified in this case and supported by the growing literature of conservative management of AVN at pre-collapse stage $(2,3,4)$. Four months later, the patient was able to walk $6 \mathrm{~km}$ daily and attend the gym regularly. Repeat MRI showed marked improvement in high signal intensity in both femoral heads, consistent with spontaneous healing of AVN (Fig. 1C and D). She remains symptoms free 4 years after adrenalectomy.

Given the histopathological diagnosis and its known association with Carney complex (CNC), genetic testing was performed but did not reveal a mutation in protein kinase A, regulatory subunit, type I, alpha (PRKAR1A) gene.

\section{Discussion}

Atraumatic AVN of the hip is typically associated with exogenous glucocorticoid treatment. To date, there have been less than 20 reports where AVN was the presenting feature of endogenous cortisol excess $(5,6)$. In the largest series to date of patients with glucocorticoid-induced AVN, only 3 of 77 patients had evidence of endogenous steroid excess (7). The mechanism by which glucocorticoidinduced AVN develops is not fully understood. It has been reported that glucocorticoids induce osteocyte apoptosis, the first histopathological feature of AVN, leading in turn to impairment in bone remodelling (8). One of the 

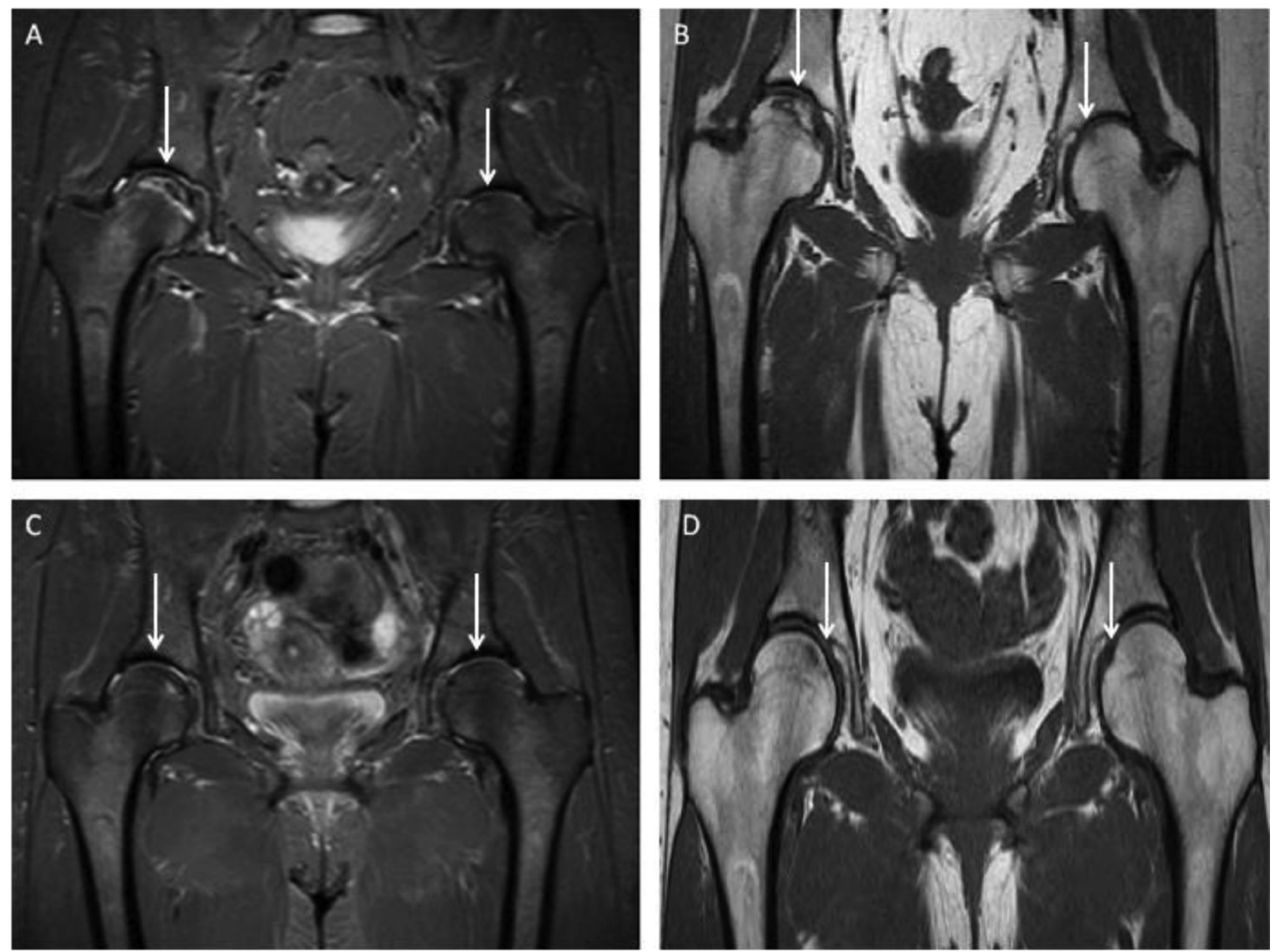

Figure 1

MRI pelvis - pre-treatment: (A) Coronal Short-T1 Inversion Recovery (STIR); (B) coronal T1. Right femoral head inner bright hyperintense and outer dark hypointense signal lines on the STR sequence and dark hypointense signal line on the T1 sequence compatible with osteonecrosis. Post-treatment: (C) coronal STR; (D) coronal T1. Near-complete resolution of right femoral head pre-treatment signal abnormality with now only a small residual bright hyperintense STR sequence and dark T1 sequence hypointense signal focus. No evidence of cortical collapse.

plausible mechanisms of steroid-induced osteonecrosis is microvascular ischaemia due to intravascular thrombi formation and lipid microemboli with resultant tissue necrosis (9). The association between glucocorticoid excess and a hypercoagulable state has been known for long. In addition to this, glucocorticoids are associated with fatcell hypertrophy in the bone marrow, leading to increased bone marrow pressure and compromised venous return (10). A recently published study reported that treatment with low-molecular-weight heparin (LMWH) prevents AVN in animal models of steroid-induced osteonecrosis supporting the theory that intravascular thrombosis plays a major role in its pathophysiology (11). Counterintuitively, two case reports have described the development of AVN following successful treatment of hypercortisolism (12)
(13). However, either no information on replacement doses of steroids was given or a supraphysiological steroid replacement regimen with prednisolone was used. It has been shown that steroid doses equivalent to less than $5 \mathrm{mg}$ of prednisolone daily can lead to abnormal ACTH and cortisol responses to Corticotropin Releasing Hormone (CRH) in normal subjects, indicating that such doses are supraphysiological (14). Although osteonecrosis of the hip is reported typically in association with prolonged courses of high doses of glucocorticoids, it has been shown that up to $2.4 \%$ of patients on replacement doses of glucocorticoids can develop this complication of hypercortisolaemia (15).

It has been suggested that, if left untreated, AVN leads to a complete collapse of the femoral head necessitating 
total hip replacement in up to $70 \%$ of patients $(8)$. The majority of the described patients with AVN due to endogenous hypercortisolaemia were treated surgically with core decompression surgeries, osteotomies or total hip arthroplasties $(6,12,16,17)$. Although hip-preserving surgical procedures remain the mainstay of treatment in cases of atraumatic AVN, a number of medical therapies targeting pathophysiological pathways in this condition, such as bisphosphonates, non-steroidal antiinflammatories and $\mathrm{LMWH}$, have been evaluated with varying clinical outcomes $(3,4,18)$. Although our patient was treated with prophylactic LMWH during her hospital stay, we do not think that this influenced the outcome as the study showing delay in progression of osteonecrosis utilised much higher doses of this medication for a longer duration (3). There is some evidence suggesting that statins can prevent osteonecrosis, but it is of note that our patient was never exposed to such treatment (19).

Here, we report the case of a 36-year-old woman with Cushing's syndrome due to primary pigmented nodular adrenocortical disease, presenting with symptomatic AVN of both hips. PPAND is associated with CNC, a rare endocrine neoplasia syndrome caused in $70-80 \%$ of cases by a mutation in the PRKAR1A gene (20). Patients with CNC have a constellation of abnormalities, including cardiac and other myxomas, spotty skin pigmentation and endocrine organ tumours (21). Evaluation of our patient revealed some skin freckling, and it was thought that this could be a feature of CNC. Because of this and the histopathological diagnosis, we performed genetic testing given the known association of this condition with tumours, including a small risk of malignancy (22). Genetic diagnosis would also have implications for the patient's family members and the patient's family planning as the condition is inherited in an autosomal dominant manner (20). It is possible that the patient might possess a somatic mutation in the PRKAR1A gene in the adrenal cells as this has been described in a significant proportion of patients with adrenal Cushing's syndrome (23), but this would not have any clinical implications for her or her family.

AVN in our case was managed conservatively from an orthopaedic perspective, and the patient's hypercortisolaemia was cured following bilateral adrenalectomy. With this approach, she experienced excellent and sustained functional recovery, and marked improvement in radiological findings was observed on MRI.

In this case, similar to others in the literature, the initial presenting symptoms were attributed to another pathology. AVN frequently evades early diagnosis, and a high index of clinical suspicion is required for its accurate identification. This case highlights that AVN can be a presenting feature of hypercortisolaemia, both endogenous and exogenous, and as such should prompt consideration of a work-up for same. This is the first report of a favourable long-term outcome following non-surgical management of AVN of the hip due to endogenous hypercortisolaemia.

\section{Declaration of interest}

The authors declare that there is no conflict of interest that could be perceived as prejudicing the impartiality of the research reported.

\section{Funding}

This research did not receive any specific grant from any funding agency in the public, commercial or not-for-profit sector.

\section{Patient consent}

Written informed consent has been obtained from the patient for publication of the submitted article and accompanying images.

\section{Author contribution statement}

A Pazderska wrote the manuscript and was involved in the care of the patient. M Sherlock provided critical review of the manuscript and was involved in the care of the patient. S Crowther, P Govender and K C Conlon provided pathological, radiological and surgical input into the patient's care. J Gibney was the primary physician of the patient.

\section{References}

1 Louiset E, Stratakis CA, Perraudin V, Griffin KJ, Libé R, Cabrol S, Fève B, Young J, Groussin L, Bertherat J, et al. 2009 The paradoxical increase in cortisol secretion induced by dexamethasone in primary pigmented nodular adrenocortical disease involves a glucocorticoid receptor-mediated effect of dexamethasone on protein kinase A catalytic subunits. Journal of Clinical Endocrinology and Metabolism 94 2406-2413. (doi:10.1210/jc.2009-0031)

2 Meizer R, Radda C, Stolz G, Kotsaris S, Petje G, Krasny C, Wlk M, Mayerhöfer M, Landsiedl F \& Aigner N 2005 MRI-controlled analysis of 104 patients with painful bone marrow edema in different joint localizations treated with the prostacyclin analogue iloprost. Wiener Klinische Wochenschrift 117 278-286. (doi:10.1007/ s00508-005-0326-y)

3 Glueck CJ, Freiberg RA, Sieve L \& Wang P 2005 Enoxaparin prevents progression of stages I and II osteonecrosis of the hip. Clinical Orthopaedics and Related Research 435 164-170.

4 Agarwala S, Jain D, Joshi VR \& Sule A 2005 Efficacy of alendronate, a bisphosphonate, in the treatment of AVN of the hip. A prospective open-label study. Rheumatology 44 352-359. (doi:10.1093/ rheumatology/keh481)

5 Takada J, Nagoya S, Kuwabara H, Kaya M \& Yamashita T 2004 Rapidly destructive coxarthropathy with osteonecrosis and osteoporosis caused by Cushing's syndrome. Orthopedics 27 1111-1113.

6 Koch CA, Tsigos C, Patronas NJ \& Papanicolaou DA 1999 Cushing's disease presenting with avascular necrosis of the hip: an orthopedic emergency. Journal of Clinical Endocrinology and Metabolism $\mathbf{8 4}$ 3010-3012. (doi:10.1210/jcem.84.9.5992) 
7 Fisher DE \& Bickel WH 1971 Corticosteroid-induced avascular necrosis. A clinical study of seventy-seven patients. Journal of Bone and Joint Surgery 53 859-873.

8 Mont MA, Jones LC \& Hungerford DS 2006 Nontraumatic osteonecrosis of the femoral head: ten years later. Journal of Bone and Joint Surgery. American Volume 88 1117-1132. (doi:10.2106/ JBJS.E.01041)

9 Glueck CJ, Freiberg R, Tracy T, Stroop D \& Wang P 1997 Thrombophilia and hypofibrinolysis: pathophysiologies of osteonecrosis. Clinical Orthopaedics and Related Research 334 43-56.

10 Motomura G, Yamamoto T, Miyanishi K, Yamashita A, Sueishi K \& Iwamoto Y 2005 Bone marrow fat-cell enlargement in early steroidinduced osteonecrosis - a histomorphometric study of autopsy cases. Pathology, Research and Practice 200 807-811. (doi:10.1016/ j.prp.2004.10.003)

11 Beckmann R, Shaheen H, Kweider N, Ghassemi A, Fragoulis A, Hermanns-Sachweh B, Pufe T, Kadyrov M \& Drescher W 2014 Enoxaparin prevents steroid-related avascular necrosis of the femoral head. Scientific World Journal 2014347813. (doi:10.1155/2014/347813)

12 Saeed A \& Bannan L 2012 Avascular necrosis of femoral heads post-adrenal surgery for Cushing's syndrome: a rare presentation. Irish Journal of Medical Science 181 263-264. (doi:10.1007/ s11845-011-0717-1)

13 Premkumar M, Dhanwal DK, Mathews S, Garg A, Sahoo S, Mahamine K \& Samad S 2013 Avascular osteonecrosis of femoral head in a postoperative patient of pituitary Cushing's disease. Journal of the Association of Physicians of India $\mathbf{6 1} 413-415$.

14 Schlaghecke R, Kornely E, Santen RT \& Ridderskamp P 1992 The effect of long-term glucocorticoid therapy on pituitary-adrenal responses to exogenous corticotropin-releasing hormone. New England Journal of Medicine 326 226-230. (doi:10.1056/NEJM199201233260403)

15 Vreden SG, Hermus AR, van Liessum PA, Pieters GF, Smals AG \& Kloppenborg PW 1991 Aseptic bone necrosis in patients on glucocorticoid replacement therapy. Netherlands Journal of Medicine 39 153-157.
16 Ko JY, Chen SH, Chen CE \& Eng HL 2004 Femoral head preservation in non-united femoral neck fracture and head osteonecrosis in Cushing's disease. Journal of the Formosan Medical Association 103 234-238.

17 Kobayashi S \& Terayama K 1991 Coxarthrosis secondary to ischemic necrosis of the femoral head in Cushing's disease. Revue de Chirurgie Orthopédique et Réparatrice de l'Appareil Moteur 77 362-365.

18 Albers A, Carli A, Routy B, Harvey EJ \& Séguin C 2015 Treatment with acetylsalicylic acid prevents short to mid-term radiographic progression of nontraumatic osteonecrosis of the femoral head: a pilot study. Canadian Journal of Surgery 58 198-205. (doi:10.1503/cjs)

19 Pritchett JW 2001 Statin therapy decreases the risk of osteonecrosis in patients receiving steroids. Clinical Orthopaedics and Related Research 386 173-178.

20 Bertherat J, Horvath A, Groussin L, Grabar S, Boikos S, Cazabat L, Libe R, René-Corail F, Stergiopoulos S, Bourdeau I, et al. 2009 Mutations in regulatory subunit type $1 \mathrm{~A}$ of cyclic adenosine 5'-monophosphate-dependent protein kinase (PRKAR1A): phenotype analysis in 353 patients and 80 different genotypes. Journal of Clinical Endocrinology and Metabolism 94 2085-2091. (doi:10.1210/ jc.2008-2333

21 Stratakis CA, Kirschner LS \& Carney JA 2001 Clinical and molecular features of the Carney complex: diagnostic criteria and recommendations for patient evaluation. Journal of Clinical Endocrinology and Metabolism 86 4041-4046. (doi:10.1210/ jcem.86.9.7903)

22 Morin E, Mete O, Wasserman JD, Joshua AM, Asa SL \& Ezzat S 2012 Carney complex with adrenal cortical carcinoma. Journal of Clinical Endocrinology and Metabolism 97 E202-E206. (doi:10.1210/jc.20112321)

23 Beuschlein F, Fassnacht M, Assié G, Calebiro D, Stratakis CA, Osswald A, Ronchi CL, Wieland T, Sbiera S, Faucz FR et al. 2014 Constitutive activation of PKA catalytic subunit in adrenal Cushing's syndrome. New England Journal of Medicine 370 1019-1028. (doi:10.1056/NEJMoa1310359)

Received in final form 28 March 2016

Accepted 11 April 2016 